REVISTA X, Curitiba, volume 14, n.6,p.44-65, 2019.

\title{
O VENEZUELANO INVASOR EM BOA VISTA (RR): UMA ANÁLISE CRÍTICA DOS DISCURSOS DE ÓDIO NO FACEBOOK
}

The Venezuelan invader in Boa Vista (RR): a critical analysis of hate discourses on Facebook

\begin{abstract}
RESUMO: A presente pesquisa objetiva desenvolver uma análise acerca dos discursos de ódio feitos em comentários de publicações do Facebook, buscando compreender como as construções linguísticas e ideológicas dos seus autores operam no processo de representação da identidade do imigrante venezuelano no Estado de Roraima. Como aporte teórico, utiliza-se a Análise Crítica do Discurso (FAIRCLOUGH, 2001; 2016), que examina a linguagem a partir de uma perspectiva social, considerando o discurso como parte constituída a partir da realidade e constituinte desta e responsável pela manutenção das relações assimétricas de poder estabelecidas pela linguagem. O corpus é composto por printscreens de comentários realizados entre os meses de janeiro e agosto de 2018 em postagens públicas relacionadas a notícias que envolvam a população venezuelana do Estado. Analisaram-se as construções textuais dos usuários da rede social, examinando como os contextos sócio, histórico e cultural atuam sobre a atividade de produção discursiva do falante. Como resultado, compreende-se que, pelos comentários, os usuários brasileiros se enxergam como responsáveis pelo bem do país e difundem a imagem do refugiado como um invasor causador de desordem e determinado a tomar aquilo que deveria pertencer aos brasileiros.
\end{abstract}

PALAVRAS-CHAVE: Análise Crítica do Discurso; Discursos de ódio; Redes sociais; Refugiados.

ABSTRACT: This research aims at developing an analysis about hate discourses on Facebook posts, seeking to understand how the author's linguistic and ideological constructions work in the process of representing the identity of the Venezuelan immigrant in Roraima. In order to develop this analysis, the theory of Critical Discourse Analysis (FAIRCLOUGH, 2001; 2016) is used, which examine language from a social perspective, considering it as a constituted and constituent aspect of reality and also responsible for the maintenance of the asymmetric relations of power established by language. The corpus is constituted by printscreens of comments made between the months of January and August of 2018 in public posts related to news that involve the Venezuelan population of the state. We analyzed the textual constructions of the social network users, examining how the social, historical and cultural contexts

\footnotetext{
1 Graduado em Letras - Português/Inglês pela Universidade Federal de Roraima (UFRR). raphaelmichels@hotmail.com

${ }^{2}$ Professora Adjunta da Universidade Federal de Roraima (UFRR) do Curso de Letras - Português/Inglês e do Mestrado em Letras (PPGL) da mesma instituição. Doutora em Letras pela Universidade Federal de Santa Catarina (USFC). julia.martins@ufrr.br
} 
act on the discursive production activity of the speaker. As a result, it is understood that by the comments, Brazilian users see themselves as responsible for the good of the country and diffuse the image of the refugee as an invader causing disorder and determined to take what should belong to Brazilians.

KEYWORDS: Critical Discourse Analysis; Hate discourse; Refugee; Social Networks.

\section{INTRODUÇÃO}

Comunicar-se e expressar opiniões são atividades que sempre fizeram parte do cotidiano em sociedade, mas que, com o advento das Redes Sociais nos últimos anos, vêm se expandindo e gerando novas formas de realização. É nesse contexto comunicacional, em que todos têm o direito à palavra, que discursos de ódio se tornam comuns e surgem disfarçados de opinião, sob o pretexto da liberdade de expressão.

Tais discursos influenciam não somente a construção da opinião coletiva por meio da assimilação de ideias - no sentido de que pessoas com ideias semelhantes se encontram e passam a identificar-se dentro de um mesmo grupo - mas também propagam e efetivam a construção da representatividade dos indivíduos em situação de vulnerabilidade. Embora a democratização do acesso à Internet permita a criação de novas formas de comunicação, esse acesso também corrobora a formação de novas ordens sociais de poder e opressão, o que pode favorecer a proliferação de discursos de ódio.

Essas "novas" posições sociais que surgem com o processo migratório no Brasil geram conflitos de caráter linguístico que perpassam os campos da linguagem e alcançam o limiar dos direitos humanos. Tal conjuntura apresenta-se ao profissional das Letras e pesquisador crítico do discurso não somente como objeto de estudo das posições sociais desempenhadas pelos sujeitos em suas interações, mas como momento de reflexão sobre o papel de cada um nesse processo.

Esta pesquisa propõe analisar a construção textual de usuários de uma rede social, a partir de discursos difamatórios veiculados em perfis públicos do Facebook, um ambiente público de anonimato imediato em que o indivíduo tem a sensação de invulnerabilidade, perpetuando, dessa forma, discursos estereotipados acerca de comunidades marginalizadas em nossa sociedade. Com a explosão migratória na região Norte após a chegada de refugiados venezuelanos, principalmente nas cidades de Boa 
Vista e Pacaraima (esta última sendo o ponto de entrada de imigrantes no país, visto sua fronteira com a Venezuela), novos impasses surgem e ganham espaço para discussão ${ }^{3}$.

A escolha do Facebook para esta pesquisa deu-se pela notória facilidade de compartilhamento de conteúdo proporcionado pela plataforma, que pode ser acessada em qualquer smartphone, permitindo, assim, a interação instantânea com a informação. Conforme demonstra a Pesquisa Brasileira de Mídia de 2015 (SECOM, 2015), o Facebook lidera o ranking das mídias sociais mais utilizadas pelos brasileiros, com $83 \%$ dos usuários, na frente de aplicativos como WhatsApp (58\%) e YouTube (17\%).

O presente trabalho, fruto de um Trabalho de Conclusão do Curso de Letras Português e Inglês da Universidade Federal de Roraima (UFRR), lança olhares sobre questões relacionadas ao modo como as relações assimétricas de poder são mantidas por meio do discurso, principalmente nas redes sociais, observando-se como o sujeito é colocado em situação desprivilegiada nessa relação de poder. Para responder tais questionamentos, realizamos revisão teórica acerca do campo da Análise Crítica do Discurso, buscando compreender como o discurso influencia na forma como percebemos o mundo e os indivíduos com quem convivemos.

\section{DISCURSO COMO PRÁTICA POLÍTICA E IDEOLÓGICA}

Refletir acerca dos estudos da linguagem a partir de um viés social implica considerar a existência de uma camada que se preocupe com a característica ideológica imanente ao usuário da língua. A esse nível de compreensão é dado o nome de discurso, "o ponto de articulação dos processos ideológicos e dos fenômenos linguísticos" (BRANDÃO, 2004, p. 11).

Norman Fairclough apresenta o discurso como sendo uma atividade da prática social, que não somente é um reflexo de interações sociais, como também é um modo de ação sobre as pessoas e sobre o próprio mundo (FAIRCLOUGH, 2001; 2016). Essa concepção entende o discurso como motivado pelas situações interacionais, isto é, molda-se às características pertencentes ao meio em que está inserido.

Dessa forma, o uso da linguagem não estaria restrito somente aos conhecimentos prévios dos usuários da língua, ou melhor, sua competência. Ao invés disso, seria

\footnotetext{
${ }^{3}$ Conforme dados da Agência da ONU para Refugiados (ACNUR), cerca de 2,6 milhões de venezuelanos vivem fora de seu país. Desses, 70\% deslocam-se para os países da América do Sul, sendo o Brasil um dos destinos dessa população. Dados do Governo Federal apontam que já foram realizadas mais de 65 mil solicitações de refúgio no Brasil por parte de venezuelanos e outras 19 mil solicitações de residência temporária. Disponível em: <http://www.acnur.org/portugues/2018/10/23/novo-abrigo-expandeacolhimento-de-venezuelanos-em-boa-vista/>. Acesso em: 04 nov. 2018.
} 
necessário compreender toda a conjuntura social para identificar os meios pelos quais o falante é levado a fazer suas escolhas linguísticas. Da mesma maneira, o discurso não só é marcado pelas características do seu entorno como também motiva a construção e a manutenção da própria estrutura que o engloba. Isso porque é por meio do discurso que as pessoas constroem suas relações e identidades sociais e é através destas que acabam por constituir a prática social.

É esse enquadramento da linguagem que a Análise Crítica do Discurso (ACD) busca observar. O ponto de partida para seu estudo está em considerar a língua como sendo historicamente situada e, assim, tendo em sua construção interferências culturais, econômicas e sociais. Dessa forma, ela deixa de ser um instrumento por meio do qual o usuário somente reproduz a sociedade e passa a ser também constitutiva desta (FAIRCLOUGH, 2001; 2016).

Por seu caráter social, a ACD é um campo de pesquisa interdisciplinar, pois utiliza-se não somente de argumentos linguísticos para a análise de seus dados, mas também dialoga com teorias advindas de outras disciplinas, como a Sociologia, a Filosofia e a História, por exemplo. Essa conversa com áreas afins permite à ACD transpor as barreiras do estudo linguístico somente pela estrutura e firmar-se como método e ferramenta de análise interpretativa da linguagem. Fairclough (2001) identifica três aspectos que representam os efeitos que o discurso tem sobre as estruturas da sociedade: ele constrói as identidades sociais, as relações sociais entre as pessoas e os sistemas de significação do mundo.

Entretanto, é importante atentar-se que essas três características constitucionais do discurso, apesar de aparentarem ter o domínio sobre a maneira como o indivíduo porta-se perante a comunidade, não fazem dele o principal mantenedor ou a fonte de toda a organização social. A característica dialógica da linguagem se aplica aqui como uma via de mão dupla, na qual o discurso sofre com os efeitos das estruturações da sociedade e ainda contribui para mantê-las ou refutá-las, conforme a perspectiva adotada pelo usuário.

Para a Análise Crítica do Discurso, o texto atua como referência, por meio do qual serão estudados os fenômenos sociais. Parte-se dele, utilizando-se insumos linguísticos e de outras áreas do conhecimento, para análise da estrutura da sociedade e da função exercida pelo texto nesse meio. O discurso atua sobre a sociedade na mesma medida em que é modificado por ela e a ACD importa-se em demonstrar como as 
relações de poder se mantêm por meio dos textos. Fairclough identifica o discurso como prática política e ideológica, segundo ele:

O discurso como prática política estabelece, mantém e transforma as relações de poder e as entidades coletivas (classes, blocos, comunidades, grupos) entre as quais existem relações de poder. $\mathrm{O}$ discurso como prática ideológica constitui, naturaliza, mantém e transforma os significados do mundo de posições diversas nas relações de poder. (FAIRCLOUGH, 2001, p. 94).

É aqui que as dimensões social e discursiva colidem, quando o texto passa a representar as construções ideológicas do produtor, evidenciando relações muitas vezes assimétricas de poder entre os usuários da língua. Tais relações demonstram problemas de "desigualdade social e manipulações discursivas" (SYLVESTRE, 2013, p. 24). Isso porque ao realizar a produção e a interpretação de um texto, todos os indivíduos envolvidos no processo de interação trazem consigo uma gama de conhecimentos já interiorizados dos quais fazem uso de maneira consciente ou não (FAIRCLOUGH, 2001).

A noção de discurso está intrinsecamente ligada à concepção de que ao produzir seus enunciados, o sujeito coloca em ação processos de significação que não desconsideram sua vivência e construções sociais. É dito que essas formações discursivas são ideologicamente carregadas das concepções de seus produtores, mantendo, assim, muitas das relações assimétricas de poder instituídas socialmente. Fairclough assim define ideologia:

Entendo que as ideologias são significações/construções da realidade (o mundo físico, as relações sociais, as identidades sociais) que são construídas em várias dimensões das formas/sentidos das práticas discursivas e que contribuem para a produção, a reprodução ou a transformação das relações de dominação. (FAIRCLOUGH, 2001, p. 117).

Segundo essa linha de pensamento, os discursos são investidos ideologicamente, isto é, o usuário da língua traz à tona em seus textos relações de poder que são, muitas vezes, impostas a ele de forma inconsciente. Os significados embutidos em tais discursos trabalham a manutenção das posições sociais e, se naturalizados, tornam-se o que conhecemos como "senso comum" (FAIRCLOUGH, 2001).

Entretanto, não é possível afirmar que um discurso será necessariamente recebido com a mesma carga semântica todas as vezes que pronunciado, isso porque os sujeitos na atividade da comunicação realizam diferentes interpretações acerca de uma 
mesma construção textual/discursiva. Essas várias interpretações dão ao discurso sua característica ideológica, uma vez que a língua, historicamente situada, passa por inúmeros processos de significação e atribuição de sentidos às formações discursivas. $\mathrm{O}$ sujeito, exposto somente à sua própria realidade e eventos discursivos, tem a impressão de que é ele originário de suas próprias palavras, quando está, por vezes, reproduzindo sentidos já estabelecidos para aquela situação. Isso não significa dizer que não é ele um indivíduo discursivamente criativo, visto que pode optar entre várias significações ideologicamente orientadas para os diversos contextos aos quais é exposto (ORLANDI, 2015).

Para Fairclough, a ideologia não se encontra apenas na estrutura discursiva, nem tão somente nos eventos discursivos, mas em ambos, visto ser "uma orientação acumulada e naturalizada que é construída nas normas e nas convenções, como também um trabalho atual de naturalização e desnaturalização de tais orientações nos eventos discursivos" (FAIRCLOUGH, 2001, p. 119).

A expressão de uma ideologia não acontece somente pela escolha das palavras de um produtor do discurso. Prender-se a essa concepção seria limitar a análise e deixar de lado vários outros recursos linguísticos que trazem em si valores sociais e que demonstram como se dão as relações de poder por meio do discurso. No contexto específico desta pesquisa, o uso de sentenças transitivas ${ }^{4}$ que colocam o venezuelano como agente usurpador de bens dos nacionais é um exemplo de como a organização frasal transparece as construções ideológicas do autor do discurso.

O processo de formação das relações de poder por meio do discurso inclui a compreensão de que os indivíduos são também criados a partir das posições ideológicas. O sujeito produtor discursivo, ao realizar essa função e expor suas construções históricas, sociais e culturais a partir do contexto e da posição que a ele é permitida, atribui também uma posição ao seu alvo. Essas imposições criam sistemas de dominação e de luta hegemônica sustentados pelos discursos, mantendo a ordem social na qual um indivíduo, ou grupo de indivíduos, é favorecido em detrimento de outro (RESENDE; RAMALHO, 2006).

Para melhor desenvolver a análise com base na $\mathrm{ACD}$, adentraremos a seguir no campo de estudos relacionados à imigração, cultura e identidade.

\footnotetext{
${ }^{4}$ Isto é, sentenças que têm como núcleo um verbo que, para sua completude, necessita de complementação: sujeito e objeto ou somente um deles.
} 
REVISTA X, Curitiba, volume 14, n.6,p.44-65, 2019.

\section{IMIGRAÇÃO, CULTURA E IDENTIDADE}

Apesar de grandes discussões a respeito do movimento migratório terem ganhado força e espaço para debate nas últimas décadas, não é recente que populações inteiras se deslocam para outros países em busca de melhores condições de vida. Observar essa movimentação envolve compreender questões que atingem o âmago da vida em sociedade, como as relações de identidade, cultura, poder e as posições sociais muitas vezes impostas aos imigrantes e refugiados.

De acordo com o Alto Comissariado das Nações Unidas para os Refugiados $(\mathrm{ACNUR})^{5}$, define-se como migrante (ou international migrant, conforme a definição utilizada pela agência) a pessoa que mora em um país diferente do seu país de nascença. A migração pode ser causada por diversos motivos, "incluindo trabalho e prosperidade, violência e insegurança, violações dos direitos humanos, crescimento ou redução populacional, mudanças na distribuição etária da população, desigualdade e mudanças estruturais no mercado de trabalho" (ONU, 2018, p. 3, tradução nossa) ${ }^{6}$.

Por sua vez, a definição de "refugiado" possui características que, mesmo aproximando-a do sentido de migrante, traz em si conjunturas que tornam a situação da pessoa em condição de refúgio ainda mais crítica e apoiada por questões legais. Tem-se como refugiado aquele que está distante do seu país de origem devido a conflitos, violência, perseguição e outras circunstâncias que ameaçam a ordem pública (UNHCR, 2016). Tais indivíduos precisam de proteção internacional, correndo riscos, por vezes de vida, em caso de retorno aos seus países.

Conforme aponta o Relatório Mundial de Migração 2018, elaborado pela Organização Internacional para as Migrações $^{7}$ (IOM, 2018), estima-se que o número de migrantes alcança 244 milhões, tendo aumentado mais de 100 milhões desde 1990, sendo que a maior parcela desses indivíduos (72\%) se encaixa na faixa etária apta ao mercado de trabalho (entre 20 e 64 anos). Esses números demonstram que é preciso dedicar atenção específica para esses indivíduos - que não devem ser encarados como um pequeno grupo.

Esse deslocamento transcende a mera concepção de mudança entre espaços geográficos, afinal, ao deixar sua terra natal para residir em outra nação, o migrante

\footnotetext{
${ }^{5}$ United Nations High Commissioner for Refugees (UNHCR), em inglês.

${ }^{6}$ Do original em inglês: "[...] including jobs and prosperity, violence and insecurity, human rights violations, population growth or decline, shifts in the population age distribution, inequality and structural changes in labour markets."

${ }^{7}$ International Organization for Migration (IOM), em inglês.
} 
carrega consigo todos os conceitos que construiu (e que foram nele embutidos) ao longo de sua vida. Sobre isso, Sarriera, Pizzinato e Meneses (2005) apontam que o processo de migração, assim como qualquer outra atividade social, envolve a mudança de contatos socioculturais do sujeito. O imigrante está sendo inserido em um novo contexto, uma nova nação com crenças e construções sociais próprias, formas de pensar e de agir diferentes e uma nova sociedade com a qual deverá se adaptar e que, por sua vez, também precisará se adaptar a esse indivíduo estrangeiro.

Todo esse contato com novas ideologias e construções sociais causa o que o comumente chamamos de "choque cultural", que é o processo de adaptação e aprendizado no qual o imigrante encontra-se dividido entre demonstrar seu melhor desempenho para se encaixar naquela realidade, mas preservando sua identidade original (MOTA; FRANCO; MOTTA, 1999). Cultura aqui "pode ser entendida como um conjunto de experiências, crenças e valores, e [...] como um campo ativo de luta e contestação" (SARRIERA; PIZZINATO; MENESES, 2005, p. 9). Nossas identidades estão diretamente ligadas à cultura da comunidade simbólica na qual nos inserimos, principalmente à comunidade natal (KETZER, 2018, p. 682). É a cultura um espaço no qual as identidades são construídas não somente pelas suas semelhanças, mas também por suas diferenças, por meio do contato com o outro. Nesse contexto, não somente a identidade do migrante sofre adaptações, mas a do seu anfitrião também, isto é, do indivíduo já residente do país no qual o estrangeiro se insere.

Seguindo essa mesma linha de raciocínio, Woodward (2000) explica que a identidade é marcada pela relação com o outro, ou seja, o sujeito é $A$ exatamente por não ser $B$. Ainda segundo ela, essa demonstração de dessemelhança entre os grupos traz à tona a percepção de que algumas diferenças são assumidas como sendo mais importantes que outras, sustentando, assim, a diferença pela exclusão.

As representações de cada sujeito são instituídas por meio da interação entre eles, utilizando-se da linguagem e dos símbolos que as representam para a atribuição de seus sentidos. O processo de representação, também um processo cultural, atua sobre a formação das identidades baseando-se em sistemas simbólicos que fornecem subsídios para reflexões acerca de questões sobre o próprio sujeito e seu papel social (WOODWARD, 2000). Ainda pensando sobre o preterimento de algumas identidades em relação a outras, e sobre a manutenção destas por meio das representações, Woodward argumenta que: 
Todas as práticas de significação que produzem significados envolvem relações de poder, incluindo o poder para definir quem é incluído e quem é excluído. A cultura molda a identidade ao dar sentido à experiência e ao tornar possível optar, entre as várias identidades possíveis, por um modo específico de subjetividade [...]. (WOODWARD, 2000, p. 19).

No contexto migratório, essas diferenças tornam-se ainda mais evidentes, visto que o repertório cultural do imigrante destoa da maioria que o rodeia ao mesmo tempo em que esse passa a se diferenciar de sua própria cultura de origem. Esse processo ocorre na tentativa de manter-se culturalmente fiel à sua nação enquanto sofre as pressões do ambiente (SARRIERA; PIZZINATO; MENESES, 2005, p. 10), uma vez que o indivíduo já está sujeito às representações que a comunidade lhe atribui. A identidade aqui é construída por meio do diálogo entre aquilo que o indivíduo foi, o seu passado, e aquilo ao qual ele é exposto no momento em que vive - "relações econômicas e políticas de subordinação e dominação" (RUTHERFORD, 1990 apud WOODWARD, 2000, p. 19).

\section{Aspectos conjunturais da imigração venezuelana em Roraima}

A crise venezuelana, que se agravou no ano de 2018 causando um maior fluxo de nacionais da Venezuela no Brasil, tem início em 2013, ano de falecimento do expresidente venezuelano, Hugo Chávez. Com a morte do seu líder, o governo, desde então, assumiu uma posição mais autoritária, com represálias muitas vezes violentas e processando civis em tribunais militares, além de toda a escassez de alimentos e de medicamentos que assola o país.

Conforme o Observatório dos Direitos Humanos (Human Rights Watch) ${ }^{8}$ :

Os venezuelanos têm deixado o seu país por diferentes motivos. A grave escassez de medicamentos, suprimentos médicos e alimentos torna extremamente difícil para muitas famílias ter acesso a cuidados básicos de saúde e garantir a alimentação de seus filhos. Uma repressão implacável do governo tem resultado em milhares de detenções arbitrárias, centenas de casos de civis julgados por tribunais militares, casos de tortura e outras violações contra pessoas detidas. Prisões arbitrárias e abusos por parte das forças de segurança, inclusive pelos serviços de inteligência, continuam. As taxas extremamente altas de crimes violentos e a hiperinflação também são

\footnotetext{
8 “A Human Rights Watch é uma organização internacional de direitos humanos, não-governamental, sem fins lucrativos, [...] reconhecida por investigações aprofundadas sobre violações de direitos humanos, elaboração de relatórios imparciais sobre essas investigações e o uso efetivo dos meios de comunicação para informar e sensibilizar diversos públicos sobre suas causas”. Disponível em: <https://www.hrw.org/pt/sobre-human-rights-watch>. Acesso em: 10 nov. 2018.
} 
fatores centrais na decisão de muitas pessoas de deixar o país (HUMAN RIGHTS WATCH, 2018, n.p.).

De acordo com os relatórios apresentados por essa organização, entre abril e novembro de 2017 cerca de 5400 pessoas já haviam sido presas por terem sido relacionadas às manifestações contra o governo venezuelano. Até janeiro de 2018, em torno de 3900 foram liberadas, mas continuavam sob processos criminais (HUMAN RIGHTS WATCH, 2017).

Tais acontecimentos levaram a população a buscar melhores condições de vida em outros países, incluindo o Brasil. De acordo com o relatório da ACNUR sobre a situação venezuelana, cerca de 800 imigrantes cruzam a fronteira de Pacaraima todos os dias, "necessitando urgentemente de assistência com documentação, abrigo, alimento e saúde" (UNHCR, 2018, p. 15, tradução nossa), entretanto, o Exército Brasileiro estima que esse número gira em torno de 416 pessoas por dia $^{9}$. Dados do Instituto Brasileiro de Geografia e Estatística (IBGE) ${ }^{10}$ demonstram que dos quase 128 mil imigrantes que entraram no Brasil por Pacaraima desde 2017, mais da metade já deixaram o país $(54 \%)$.

Não é raro encontrar pelas ruas de Boa Vista, capital do Estado de Roraima, grandes grupos de imigrantes que buscam por ajuda financeira ou emprego, o que, talvez, seja a maior motivação para que os refugiados e imigrantes deixem seu país. Vasconcelos (2018) argumenta que a necessidade por alimento é uma das pulsões que coloca o sujeito em movimento, expondo-o a situações de fragilidade, mas também revelando suas capacidades. Conforme a autora, essa busca constante tem como consequências:

Por um lado, gera relações de dependência econômica com os/as brasileiros/as, por outro, ocasiona o empoderamento de provedores/as de famílias transnacionais e contribui para a comunhão entre pessoas de origens diferentes que enfrentam dificuldades semelhantes (VASCONCELOS, 2018, p. 136).

Essa é somente uma das formas pelas quais os imigrantes são colocados em posição de dominação em relação aos nacionais, que alimentam a crença de que o indivíduo estrangeiro possui menos direitos por não ter nascido no Brasil, indo contra

\footnotetext{
${ }^{9}$ G1 Roraima. 54\% dos venezuelanos que entraram no Brasil por RR desde 2017 já deixaram o país, diz ministro. Disponível em: <https://g1.globo.com/rr/roraima/noticia/54-dos-venezuelanos-queentraram-no-brasil-por-rr-desde-2017-ja-deixaram-o-pais-diz-ministro.ghtml>. Acesso em: 14 nov. 2018.

${ }^{10} \mathrm{Cf}$. nota de rodapé 9.
} 
concepções básicas dos direitos humanos. É garantido pela Declaração Universal dos Direitos Humanos (Assembleia Geral da ONU, 1948), em seu artigo 13º, segundo parágrafo, que "todo ser humano tem o direito de deixar qualquer país, inclusive o próprio e a esse regressar". No Brasil, a nova lei de Migração que substituiu o antigo dispositivo - o Estatuto do Estrangeiro - é apresentada como inovação jurídica na proteção dos direitos de estrangeiros, de uma forma geral. A nova Lei de Migração, Lei $\mathrm{n}^{\mathrm{o}} 13.445$, de 24 de maio de 2017, assegura, em seu artigo $3^{\circ}$, entre seus incisos, os seguintes pontos:

$[\ldots]$

IX - igualdade de tratamento e de oportunidade ao migrante e a seus familiares;

$\mathrm{X}$ - inclusão social, laboral e produtiva do migrante por meio de políticas públicas;

XI - acesso igualitário e livre do migrante a serviços, programas e benefícios sociais, bens públicos, educação,

assistência jurídica integral pública, trabalho, moradia, serviço bancário e seguridade social;

$[\ldots]$

XXII - repúdio a práticas de expulsão ou de deportação coletivas. (BRASIL, 2017, p. 2)

De acordo com a lei, o indivíduo em situação de imigração tem a ele assegurado os principais direitos para inclusão na sociedade, entre eles o de igualdade de tratamento e de oportunidades, além de vários outros direitos proporcionados também ao nacional. O documento não visa atribuir aos imigrantes condições que os privilegiem em relação ao brasileiro, mas que os coloquem em situação de igualdade social e econômica, para que tenham condições dignas de sobrevivência no país receptor.

Como explicam Dutra e Gayer (2015), é necessário reconhecer as diferenças para que a igualdade possa ser real. Isto significa dizer que cada grupo de indivíduos possui suas próprias necessidades que são atendidas de maneiras diversas. É preciso ter conhecimento dessas necessidades e tratá-las de maneira diferente para que todas sejam alcançadas de forma apropriada. Além disso, "tratar desigualmente não se refere à instituição de privilégios, e sim, à disponibilização das condições exigidas pelas peculiaridades individuais na garantia da igualdade real" (DUTRA; GAYER, 2015, p. 2).

No Brasil, mais especificamente em Roraima, tais direitos são muitas vezes negados aos imigrantes e refugiados, que ocupam uma das camadas mais marginalizadas da sociedade. Direitos mínimos para sobrevivência, quando atribuídos, 
são julgados como atitudes excessivas ou que visam o desprestígio da população brasileira, o que na prática não apresenta o menor risco para os nacionais, uma vez que mais direitos para os indivíduos de um país - sejam eles brasileiros ou não - não acarreta na diminuição imediata e direta de direitos à população como um todo, ou seja, mais direitos para uns não indica menos direito para outros, significa apenas maior equidade e justiça social para a sociedade como um todo.

Entretanto, em oposição a essa crença, Bastos defende que "os mesmos grandes números que entram pela fronteira e se instalam do lado de cá são precisamente o motor - ou mais precisamente o combustível - da economia contemporânea" (BASTOS, 2009, p. 131), afinal, são esses indivíduos que realizam tarefas às quais o próprio brasileiro não se sujeita a realizar e ainda a preços mais baixos, em inequívoca relação desigual de posição trabalhista. Sem falar que muitos possuem nível de escolaridade alta e profissões estratégicas nas áreas da engenharia, biomedicina, administração, mas que devido a uma junção de fatores, que vão desde a burocracia estatal, desinteresse político até o preconceito dos empresários locais, não conseguem se inserir no mercado de trabalho brasileiro em suas áreas de origem.

Está entre os desafios da nação, como apontados pelo relatório da ACNUR sobre as ações na Venezuela (2018), assegurar direitos em relação ao território, registro, documentação, abrigo, segurança, alimentação e demais aspectos necessários para uma vida digna. Para isso, é preciso gerar melhorias em vários aspectos organizacionais referentes à recebida dessa população. Aspectos que perpassem pelas questões materiais e organizacionais diretamente ligadas ao bem-estar desses indivíduos, que incitem receptividade e apoio por parte da população nacional, que desempenha um papel relevante no processo de adaptação do imigrante à sua nova sociedade.

Expostos esses pontos e feito entender a importância da relação com o outro para a manutenção das identidades sociais, partimos para a discussão dos dados gerados a partir dos comentários no Facebook relacionados aos refugiados venezuelanos em Roraima.

\section{METODOLOGIA E MACROANÁLISE DOS COMENTÁRIOS}

Os dados utilizados para o corpus original do trabalho foram retirados de comentários em postagens públicas no Facebook, em perfis abertos e/ou páginas de debate com temas específicos e que, em algum momento, trataram sobre a temática aqui abordada, entre os meses de janeiro e agosto de 2018. 
A obtenção dessas informações foi realizada por meio de pesquisa utilizando o mecanismo de busca disponibilizado pelo próprio Facebook, que utiliza palavras-chave para procurar em seus bancos de dados publicações em que tais termos aparecem. Assim, palavras como imigrantes, venezuelanos, refugiados, além de termos mais específicos relacionados a situações pontuais, foram utilizadas para localizar essas publicações. Terminada a pesquisa, foram selecionadas postagens em que havia interação dos usuários com a notícia por meio das reações da rede social e da seção de comentários, sem uma quantidade mínima de adesão estabelecida para a seleção das publicações. A partir disso, foi feita a captura de imagens (conhecida como printscreen ou simplesmente print) desse material. A seleção dos dados a serem utilizados foi feita de forma que fossem incluídos na pesquisa somente comentários que demonstrassem potencial para desenvolvimento da argumentação e da análise dos dados. Sendo assim, foram desconsiderados para este corpus comentários compostos por somente uma palavra ("Apoiado" / "Misericórdia!", entre outros), visto a escolha por analisar os sintagmas a partir das relações sintáticas estabelecidas dentro das frases.

Vale mencionar que em nenhum momento a identidade dos autores dos comentários foi divulgada publicamente, evitando possíveis reações contrárias e discussões maiores. Para evitar eventuais problemas na ordem da pesquisa, consultamos os Termos de Serviço do Facebook, que em seu item 3, subitem 3, alega que o usuário da rede social, ao criar sua conta, concorda que as publicações realizadas são públicas, transferíveis e não exclusivas, podendo ser visualizadas por qualquer um de acordo com as configurações de privacidade do usuário.

A escolha dos dados deu-se, primordialmente, pelo atual contexto político e social no qual esta pesquisa se insere. Visto que a imigração venezuelana na cidade de Boa Vista (RR) é um dos assuntos recorrentes nas discussões (científicas ou não), é natural aos residentes do Estado que o tema desperte diferentes abordagens científicas e metodológicas que busquem compreender diversos aspectos das relações desenvolvidas por meio do contato fronteiriço. Os dados obtidos têm como foco a representação dos povos venezuelanos que migraram para o Brasil e lidam constantemente com discursos discriminatórios e carregados de características xenofóbicas.

No presente trabalho, o discurso é entendido como prática política e ideológica, ambas interconectadas e interdependentes, cujo recorte analisa os comentários feitos por 
usuários na rede social e situa-os no âmbito das dimensões políticas e ideológicas da prática discursa, pois como bem explica Fairclough:

\begin{abstract}
A ideologia são os significados gerados em relação de poder como dimensão do exercício do poder e da luta pelo poder. Assim, a prática política é a categoria superior. Além disso, o discurso como prática política é não apenas um local de luta de poder, mas também um marco delimitador na luta de poder: a prática discursiva recorre a convenções que naturalizam relações de poder, ideologias particulares e as próprias convenções, e os modos em que se articulam são um foco de luta (FAIRCLOUGH, 2016, p. 98-99).
\end{abstract}

É nesse sentido que utilizamos como recorte os comentários que apresentavam como característica principal a crença do brasileiro como detentor da posse do país, responsável pela salvação da pátria e que encara o imigrante venezuelano como aquele que invade esse território visando a desestabilização da vida em sociedade, pois essa crença ajuda a construir o discurso de desprezo e exclusão em torno dos migrantes e refugiados que residem em Boa Vista, fomentando práticas xenofóbicas e reacionárias como práticas políticas e ideológicas aceitáveis, quando, na verdade, precisam ser ressignificadas e substituídas.

O caso a ser apresentado a seguir faz referência à notícia sobre a expulsão da comunidade venezuelana de Pacaraima, no norte do Estado de Roraima, no dia 18 de agosto de 2018, após uma tentativa de assalto e espancamento de um comerciante brasileiro realizada por venezuelanos. O ocorrido gerou revolta entre a população brasileira residente no local, que organizou uma manifestação contra os imigrantes presentes na cidade, resultando na vandalização dos bens materiais desses refugiados. A confusão gerou um confronto entre os dois grupos, que passaram para a agressão mútua, até o momento em que os refugiados foram forçados a deslocarem-se para o lado venezuelano da fronteira. ${ }^{11}$ Para exemplificar a forma como a notícia foi tratada pelos usuários do Facebook, apresentamos a seguir (Figura 1) uma publicação criada acerca do evento, na qual o usuário postou um vídeo com imagens do ocorrido.

\footnotetext{
11 Reportagem da Folha de São Paulo, de 18 de agosto de 2018. Venezuelanos e brasileiros se confrontam nas ruas de cidade de Roraima. Disponível em:

<https://www1.folha.uol.com.br/mundo/2018/08/refugiados-venezuelanos-sao-agredidos-e-expulsos-detendas-em-roraima.shtml>. Acesso em: 23 set. 2018.
} 
REVISTA X, Curitiba, volume 14, n.6,p. 44-65, 2019.

Figura 1 - Publicação sobre a expulsão de venezuelanos de Pacaraima (RR)

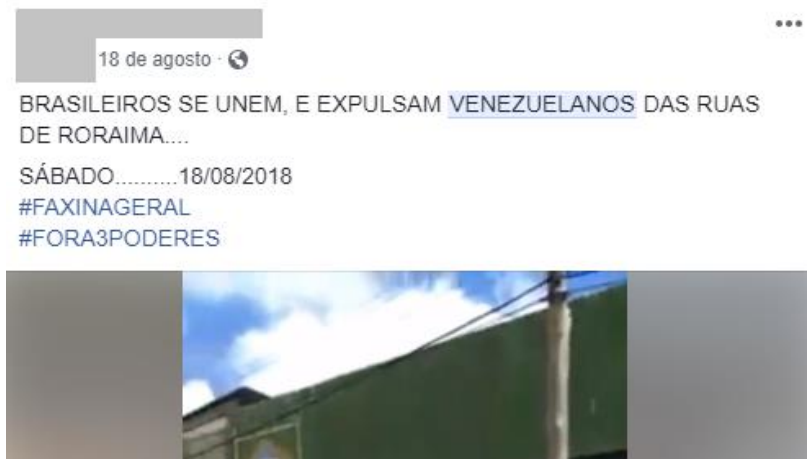

Fonte: Facebook.

A repercussão desse incidente deu-se não somente pela mídia, mas grande parte da população roraimense (ainda que não se restringindo somente a esse Estado) compartilhou em suas redes sociais notícias sobre o caso. Não é possível estimar em números a porcentagem de usuários que concordavam ou discordavam do ato em si, mas apresentamos alguns dos comentários referentes à notícia, conforme resposta à publicação do vídeo do acontecimento.

Os comentários feitos na publicação demonstram a crença compartilhada pelos brasileiros que comentaram na postagem de que a presença dos refugiados venezuelanos em Roraima é o motivo de muitos dos problemas pelos quais o Estado passa. Os discursos, como argumentam Resende e Ramalho (2006), advêm de práticas sociais que comportam interesses particulares e a utilização de uma voz ao invés de outra são aspectos que assinalam o posicionamento do autor (figuras que seguem).

Figura 2 - Printscreen 1

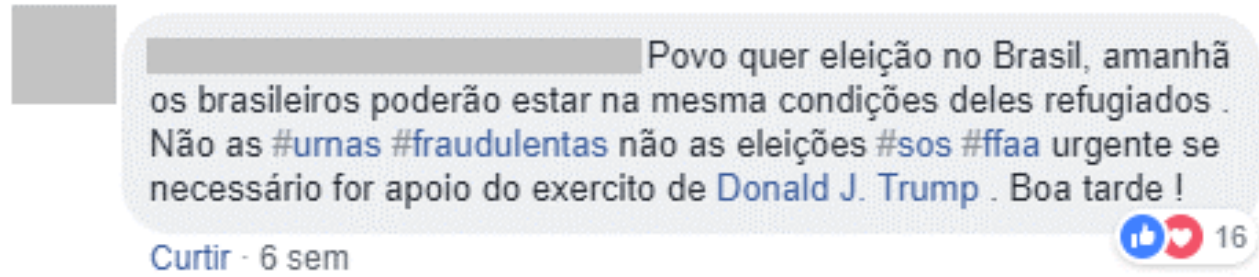

Fonte: Facebook.

Na Figura 2 acima, o usuário baseia seu discurso na ideia principal de que a solução para o problema seria a intervenção militar. $\mathrm{O}$ autor utiliza-se de um recurso comparativo para alcançar o leitor ao dizer que "[...] amanhã os brasileiros poderão estar na mesma condições (sic) deles refugiados (sic)". O comentário alimenta a crença de que o brasileiro desempenha papel superior em detrimento do venezuelano, em condição de refúgio, uma vez que a partir disso podemos pressupor que "hoje o 
brasileiro encontra-se econômica e socialmente estável, não havendo a necessidade de buscar abrigo em outros países".

O discurso de apego ao nacionalismo do comentário na Figura 2 completa-se com a passagem "Não as \#urnas \#fraudulentas não as eleições \#sos \#ffaa urgente se necessário for apoio do exercito (sic) de Donald J. Trump”. Esse trecho expõe o desejo pela intervenção militar na causa. A princípio isso pode não estar claro, entretanto, buscando o significado das siglas que o usuário utilizou em seu discurso, descobrimos que FFAA é um termo utilizado para designar as forças armadas brasileiras. Podemos nos aprofundar na análise do contexto e observar que tal desejo completa-se com a menção do atual presidente americano Donald J. Trump, que durante o período de eleições dos Estados Unidos em 2016, construiu toda sua campanha política em torno da valorização extrema do cidadão americano em detrimento às outras nacionalidades que vivem nos EUA, especialmente latinos, buscando a todo custo expulsar essas comunidades do país, bem como criar um discurso de desprezo e ódio em torno delas.

Verifiquemos agora a figura abaixo:

Figura 3 - Printscreen 2

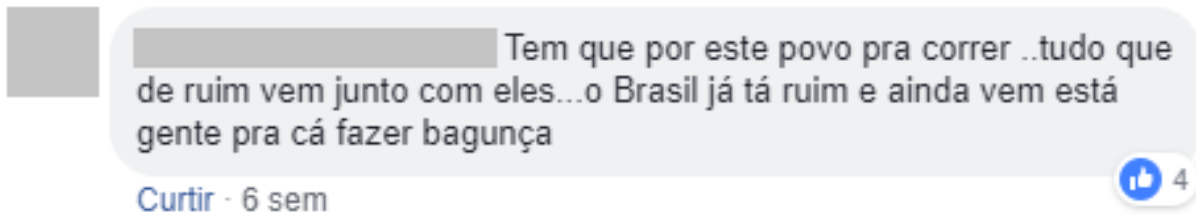

Fonte: Facebook.

No comentário apresentado na Figura 3, o discurso ainda demonstra a vontade de que os imigrantes deixem o Estado, mas é também explicitada a convicção de que são os venezuelanos os responsáveis pelas calamidades que acometem a população brasileira. A manutenção das identidades dos indivíduos acontece por meio de processos de representação que não dependem somente do sujeito alvo dessa identificação. Para Woodward (2000), os significados e identidades são construídos a partir de um sistema simbólico no qual o sujeito está inserido. Por não ser objetivo desta pesquisa debater acerca das representações jornalísticas dos imigrantes e refugiados, não nos atemos a esse tipo de representação, mas vale ressaltar que em Roraima é de senso comum discursos que coloquem a nacionalidade venezuelana em destaque nas notícias e anúncios nos quais esses indivíduos estão inseridos. Dessa forma, esse aspecto de suas 
identidades acaba por ser sempre associado às más atitudes tomadas por alguns grupos e relembrado quando for conveniente utilizar para pré-julgamentos.

O comentário na Figura 3 ("Tem que por este povo pra correr ...tudo de ruim (sic) vem junto com eles...o Brasil já tá (sic) ruim e ainda vem está (sic) gente pra cá fazer bagunça") traz marcações que trabalham o processo de marginalização dos refugiados. A utilização de “este povo" e "está (sic) gente” para designá-los é uma marca de afastamento entre 'Eles' e 'Nós (brasileiros)'. Expressões como essas, nas quais são empregados pronomes demonstrativos antes de substantivos como gente e povo, são socialmente utilizadas para manifestar um nível de desprezo em relação ao alvo da enunciação, que, por diferentes aspectos, é visto pelo falante como ocupante de uma posição inferior à sua: "não se misture com essa gente" ou "eu não gosto desse povo" são estruturas semelhantes à utilizada pelo usuário.

Associado ao uso dessa expressão temos a presença de um verbo modal "ter que", que expressa uma modalidade deôntica no discurso, isto é, neste caso uma obrigatoriedade ou necessidade de realização de algo. Fairclough (2001), ao analisar aspectos da coesão textual, identifica a importância da observação de elementos como esse nas estruturas das frases para determinar "a espécie de argumentação que é usada e a espécie de padrões de racionalidade que ela pressupõe; isso, por sua vez, nos dará alguma percepção dos tipos de identidade social que são construídos no texto" (FAIRCLOUGH, 2001, p. 213). No caso particular do discurso presente no comentário, a ação obrigatória refere-se à expulsão dos refugiados, colocando-os ainda mais em uma posição de subordinação às vontades dos nacionais.

A ideia de que os imigrantes são responsáveis pela "bagunça" no Estado aparece também no segundo comentário da Figura 4 (“As autoridades fingem de mortos é o povo que vai consertar esta bagunça"):

Figura 4 - Printscreen 3

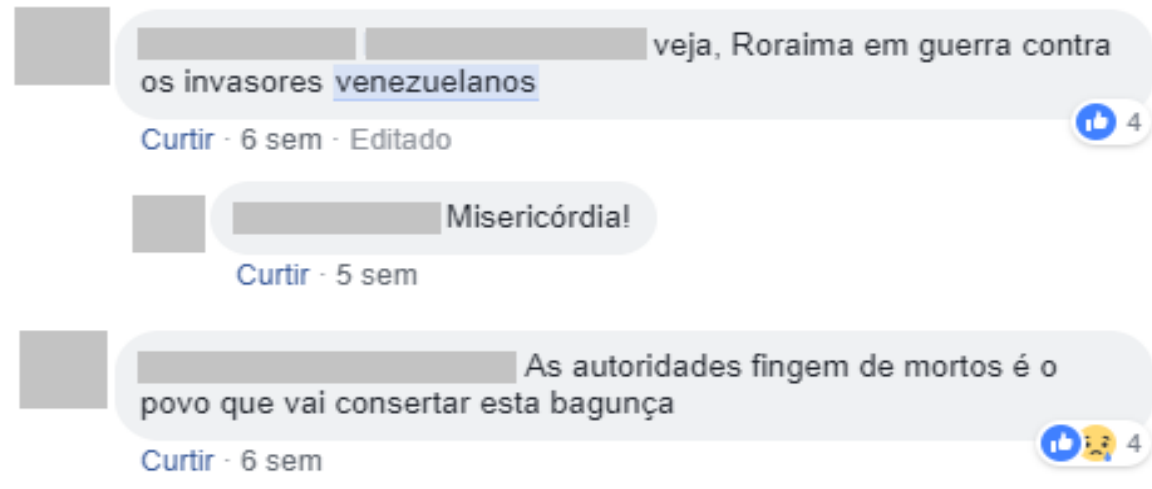

Fonte: Facebook. 
A ideia de inferioridade atribuída a nacionais de outros países corrobora a representação do refugiado como baderneiro e barulhento, como aqueles que trouxeram todos os maus costumes que tinham em seu país, principalmente quando se observa a alta concentração de imigrantes em locais públicos, alterando a paisagem da cidade antes composta por brasileiros; hodiernamente composta por venezuelanos em situação de refúgio.

É essa ocupação de prédios e praças por centenas de famílias que cria a representação dos venezuelanos como invasores. Para exemplificar, utilizamos o primeiro comentário da Figura 3, no qual o autor diz "Roraima em guerra contra os invasores venezuelanos". Aqui, a situação é comparada a uma guerra, na qual de um lado estão os nacionais brasileiros e de outro o refugiado, que é automaticamente ressignificado como um 'invasor' do ponto de vista do brasileiro, já que suas formas de ingresso no país não coincidem com as maneiras realizadas por indivíduos mais bem favorecidos economicamente, geralmente com foco em turismo, negócios ou residência permanente em situação não-vulnerável.

Podemos identificar ainda a ideia de posse atribuída ao país pelos brasileiros, conforme comentários da Figura 5, a seguir:

Figura 5 - Printscreen 4

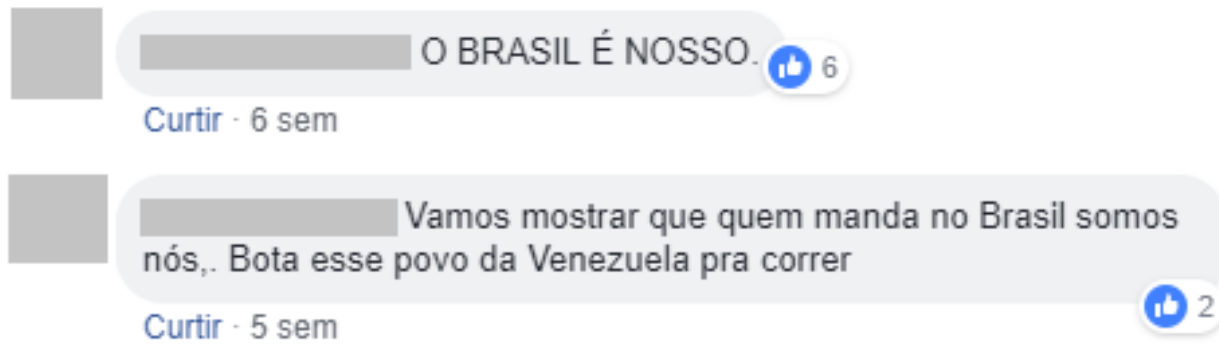

Fonte: Facebook.

O sujeito constrói seu discurso sobre a noção de Brasil como território exclusivo de nacionais brasileiros. Por meio da sentença "O BRASIL É NOSSO", o autor utiliza pronomes possessivos, 'nosso', atribuindo essa posse ao agente da oração (no caso, àqueles que aqui nasceram) e objetificando o país. A utilização do texto escrito completamente em caixa alta é também um recurso que demonstra a emoção do falante. Se pensarmos na netiqueta ou "etiqueta da Internet", a utilização de textos nesse estilo pressupõe que o autor está exaltado, gritando ou manifestando de forma grosseira seu posicionamento. Em outras palavras, a caixa alta é um recurso que demonstra entusiasmo na fala. 
A mesma ideia de posse acontece no comentário seguinte (cf. Figura 5), em "Vamos mostrar que quem manda no Brasil somos nós (brasileiros)", onde 'Brasil' é o tema da ação de ser subordinado a alguém. Aqui o autor ainda faz um apelo aos outros brasileiros ao 'pedir' que, junto a ele, mostrem quem manda no país. Ele ainda conclui com "Bota esse povo da Venezuela pra correr", sendo mais uma vez utilizada a expressão ‘esse povo’ para se referir aos imigrantes e rebaixá-los. A expressão ‘botar pra correr' é empregada no sentido de 'expulsar'. Esses comentários evidenciam o discurso xenofóbico presente na fala dos usuários, que propagam o ódio independente da real situação do alvo.

\section{CONSIDERAÇÕES FINAIS}

Os dados apresentados, printscreens de comentários no Facebook em relação à situação dos venezuelanos em Roraima, constataram, primordialmente, que os brasileiros que se manifestaram nos comentários demonstram por meio de seus discursos a imagem criada do refugiado como um invasor que visa tirar dos nacionais aquilo que deveria pertencer a eles - empregos, vagas de estudo, ajuda governamental, entre outros - isso porque, conforme proposto por Fairclough $(2001$; 2016), percebemos o discurso como sendo construído pela interação, não somente entre falantes, mas também do usuário com o contexto no qual se insere. Essa perspectiva de estudo da língua a percebe como um aspecto essencial para a manutenção das realidades (no que diz respeito à realidade, nos referimos às posições sociais de sujeito, formação das identidades, relações de poder e outras características intrínsecas às relações sociais).

As construções ideológicas tornam-se senso comum a partir do momento em que se naturalizam (FAIRCLOUGH, 2001; 2016) a ponto de serem reproduzidas quase que instantaneamente. Comentários no Facebook como "Tem que por este povo pra correr... tudo que de (sic) ruim vem junto com eles" caracterizam a ideia propagada de que a presença de venezuelanos no Estado acarreta problemas sociais e econômicos para os brasileiros, que se sentem explorados pelos imigrantes. Os discursos dos brasileiros dos comentários analisados aqui são repletos de recursos linguísticos que expressam sentido de posse por tudo que é nacional. Pronomes como "nosso" e expressões que reflitam a ideia de propriedade (“[...] quem manda no Brasil somos nós [...]”) são utilizados de forma a beneficiar o brasileiro em detrimento do estrangeiro, afastando deste qualquer direito que ele possa possuir. 
A separação entre os grupos é explicitada de diferentes formas pelos discursos dos nacionais, seja utilizando pronomes de diferenciação como "nós [brasileiros]" e "eles [venezuelanos]", seja utilizando os pronomes de posse - "nosso país" - ou ainda por meio de termos que unificam a população brasileira de forma metonímica (como pela utilização de "Brasil" para se referir aos brasileiros). Dessa forma, a identidade venezuelana é acentuada, criando a relação de diferença entre os indivíduos e, logo, de exclusão em decorrência dessa dissemelhança (WOODWARD, 2000).

Não somente isso, mas o próprio brasileiro se identificou como o "justiceiro salvador da pátria", os únicos que poderiam fazer algo para expulsar os refugiados do país. Dizemos isto porque os discursos expressavam desejos de ações como ir às ruas, colocar a população em guerra contra os "invasores", "mostrar que quem manda no Brasil" são os brasileiros ou "consertar" a bagunça causada pelos venezuelanos, são comentários que colocam os nacionais como defensores da ordem e dos desejos do Brasil, como se este fosse realmente o desejo do país.

Os imigrantes e refugiados venezuelanos passaram a representar metonimicamente o ódio do brasileiro pelo estrangeiro. $\mathrm{O}$ falante, um sujeito interpelado ideologicamente, ao produzir seus discursos está realizando um processo de significação do mundo a partir da sua vivência, no caso em questão, a vivência entre venezuelanos e brasileiros residentes em Roraima. Essas atividades linguísticas, muitas vezes, não são construídas de forma proposital, uma vez que a estruturação de seu pensamento segue padrões estabelecidos histórica e socialmente que nem sempre são acessíveis de maneira consciente.

Objetivamos demonstrar como nas construções linguísticas dos haters - aqueles que manifestam ódio pela Internet - transparecem discursos baseados em ideologias segregadoras e xenofóbicas, que buscam somente distanciar a comunidade imigrante de característica que os assemelhe aos brasileiros. Estes, inseridos em um contexto de crise política na fronteira com o Brasil, temem que a presença dos refugiados transforme o país no caos político, social e econômico semelhante ao da Venezuela. A desigualdade social aliada ao medo, ao desconhecimento e à intolerância, aflige aqueles que aqui já residiam, receosos de que a presença dos venezuelanos se apresente como uma ameaça à qualidade de vida dos brasileiros residentes em Roraima.

\section{REFERÊNCIAS}


REVISTA X, Curitiba, volume 14, n.6,p.44-65, 2019.

ASSEMBLEIA GERAL DA ONU. Declaração Universal dos Direitos Humanos. Paris. 10 dez. 1948. Disponível em: <https://www.un.org/en/universal-declaration-humanrights/>. Acesso em: 10 nov. 2018.

BASTOS, C. O Medo dos Imigrantes. In: LECHNER, E. (Org). Migração, Saúde e Diversidade Cultural. Lisboa: Imprensa de Ciências Sociais, 2009. p. 127-136.

BRANDÃO, H. Introdução à análise do discurso. $2^{\mathrm{a}}$ ed. Campinas: Editora da UNICAMP, 2004. 122p.

BRASIL. Lei $\mathrm{n}^{\circ}$ 13.445, de 24 de maio de 2017. Institui a Lei de Migração. Diário Oficial [da] República Federativa do Brasil, Brasília, 25 mai. 2017. Disponível em: <http://www.planalto.gov.br/ccivil_03/_Ato2015-2018/2017/Lei/L13445.htm>. Acesso em: 10 nov. 2018.

DUTRA, C.; GAYER, S. A inclusão social dos imigrantes haitianos, senegaleses e ganeses no Brasil. In: Seminário Internacional de Demandas Sociais e Políticas Públicas na Sociedade Contemporânea, 12., Santa Cruz do Sul, Rio Grande do Sul, 2015.

FAIRCLOUGH, N. Discurso e mudança social. Brasília: Editora Universidade de Brasília, 2001.

FAIRCLOUGH, N. Discurso e mudança social. Brasília: Editora Universidade de Brasília, 2016.

HUMAN RIGHTS WATCH. O êxodo venezuelano: A necessidade de uma resposta regional a uma crise migratória sem precedentes. Disponível em: <https://www.hrw.org/pt/report/2018/09/03/322156\#page>. Acesso em: 10 nov. 2018.

HUMAN RIGHTS WATCH. Venezuela: World Report. Disponível em: <https://www.hrw.org/pt/world-report/2018/country-chapters/313461>. Acesso em: 10 nov. 2018.

INTERNATIONAL ORGANIZATION FOR MIGRATION. World Migration Report 2018. [S. 1.], 2017. 364p. Disponível em: <https://www.iom.int/wmr/world-migrationreport-2018>. Acesso em: 03 nov. 2018.

KETZER, L. et al. Imigração, identidade e multiculturalismo nas organizações brasileiras. Interações, Campo Grande, v. 19, n. 3, p. 679-696, Jul./Set. 2018.

LAKOFF, G.; JOHNSON, M. Metaphors we live by. Chicago: University of Chicago Press, 1980.

MOTA, E.; FRANCO, A.; MOTTA, M. Migração, estresse e fatores psicossociais na determinação da saúde da criança. Psicologia, Reflexão e Crítica, Porto Alegre, v. 12, n. 1, p. 119-132, 1999. Disponível em:

<http://www.scielo.br/scielo.php?script=sci_arttext\&pid=S0102-

$79721999000100008 \& \operatorname{lng}=\mathrm{en} \& n r m=i$ so\&tlng=pt $>$. Acesso em: 03 nov. 2018. 
ONU. International Migration and Development. Report of the Secretary General. New York: General Assembly, 2018.

ORLANDI, E. P. Análise de Discurso: Princípios e procedimentos. 12.ed. Campinas: Ed. Pontes, 2015.

SYLVESTRE, A. O Eu e o Outro Online: discurso, poder e identidade nas redes sociais. 2013. 156f. Dissertação (Mestrado em Linguística) - Programa de Pós-Graduação em Linguística, Departamento de Linguística, Português e Língua Clássicas, Instituto de Letras, Universidade de Brasília, Brasília, 2013.

RESENDE, V.; RAMALHO, V. Análise de discurso crítica. São Paulo: Contexto, 2006. $158 \mathrm{p}$.

SARRIERA, J.; PIZZINATO, A.; MENESES, M. Aspectos psicossociais da imigração familiar na Grande Porto Alegre. Natal, v. 10, n. 1, p. 5-13, 2005.

SECRETARIA DE COMUNICAÇÃO SOCIAL DA PRESIDÊNCIA DA REPÚBLICA. Pesquisa Brasileira de Mídia de 2015. Disponível em:

$<$ http://www.cultura.gov.br/documents/10883/1360136/Anexo+Adicional+IV+-

+Pesquisa+SECOM+m\%C3\%ADdia.pdf/42cb6d27-b497-4742-882f-2379e444de56>.

Acesso em: 15 abr. 2018.

UNITED NATIONS HIGH COMMISSIONER FOR REFUGEES. 'Refugees' and 'Migrants'. 16 mar. 2016. Disponível em:

<http://www.unhcr.org/afr/news/latest/2016/3/56e95c676/refugees-migrants-frequentlyaskedques\%20\%F4\%80\%86\%9F\%20ons-faqs.html>. Acesso em: 02 nov. 2018.

UNITED NATIONS HIGH COMMISSIONER FOR REFUGEES. Venezuela Situation: Responding to the needs of people displaced from Venezuela, Supplementary Appeal January-December 2018. Mar. 2018. Disponível em: $<$ http://reporting.unhcr.org/sites/default/files/unhcr\%20venezuela\%20situation\%202018 \%20supplementary\%20appeal.pdf>. Acesso em: 10 nov. 2018.

VASCONCELOS, I. Receber, enviar e compartilhar comida: aspectos da migração venezuelana em Boa Vista, Brasil. REMHU, Rev. Interdiscip. Mobil. Hum., Brasília, v. 26, n. 53, ago. 2018, p. 135-151.

WOODWARD, K. Identidade e diferença: uma introdução teórica e conceitual. In: SILVA, Thomaz T. da (Org.). Identidade e diferença: a perspectiva dos estudos culturais. Petrópolis: Vozes, 2000. 